J. Agrifarm : Vol. 8 No. 2, Desember 2019 P- ISSN : 2301-9700, E- ISSN : 2540-8892

\title{
Komposisi Fraksi Pasir dan Sifat Kimia Tanah Pada Areal Revegetasi Lahan Bekas Tambang Batubara
}

\section{Composition of Sand Fraction and Soil Chemical Properties at Revegetation Area at coal Mined Land}

\author{
Ria Rachel Paranoan \\ Tenaga Pendidik Program Studi Agroteknologi, Fakultas Pertanian, Universitas Mulawarman \\ Jl. Pasir Balengkong, Kota Samarinda, Kalimantan Timur 7517 \\ Email: rachelria_paranoan@yahoo.co.id
}

Diterima : 3 Desember 2019 Disetujui : 31 Desember 2019

\begin{abstract}
The purpose of this research were to determine the composition of sand fraction and chemical properties at revegetation area. The research was conducted from April to October 2019. The mineralogical Compositions of sand fraction were analyzed using a Polarizing Microscope (PM) at the laboratory of Mineral BB Litbang SDLP, Bogor. The results showed that the composition of sand fractionof soil at revegetation area was dominatd by quartz, with small amounts of opaque, zircon,weathered mineral, rock fragment, and tourmaline.Chemical properties indicated that the soil at revegetation area showed $\mathrm{pH}$ from 6,05 to 6,49, had low content of cation exchange capacity in the whole layers, very high content of base saturation, very low to low organic carbon. Exchangeable K and Na are low in the whole layers, the moderate content of potential potassium. Both exchangeable Ca and Mg were lot to moderate. Potentioal P content in soil varies from moderate to high.Soil management in revegetation area should be focused on Maintaining soil fertility through application of liming, and fertilizers.
\end{abstract}

Keywords: Chemical Properties, Composition of sand fraction, Revegetation

\section{PENDAHULUAN}

Kegiatan penambangan batubara disatu sisi dapat meningkatkan pertumbuhan ekonomi, tetapi dilain sisi dapat mengakibatkan kerusakan lingkungan berupa penurunan produktivitas lahan, salah satu diantaranya adalah penurunan sifat kimia tanah.

Kegiatan pascatambang yang selanjutnaya disebut pascatambang, adalah kegiatan terencana, sistematis, dan berlanjut setelah akhir sebagian atau seluruh kegiatan usaha pertambangan untuk memulihkan fungsi lingkungan alam dan fungsi sosial menurut kondisi lokal di seluruh wilayah pertambangan. Reklamasi adalah kegiatan yang dilakukan sepanjang tahapan usaha pertambangan untuk menata, memulihkan dan memperbaiki kualitas lingkungan dan ekosistem agar dapat berfungsi kembali sesuai peruntukkannya (Peraturan Menteri ESDM No.7 Tahun 2014).

Menurut Pattimahu (2004), kondisi sifat kimia pada lahan bekas tambang menunjukkan bahwa rendahnya kesuburan tanah, $\mathrm{pH}$, serta kandungan nutrisi di dalam tanah.

Mineral fraksi pasir dan sifat kimia tanah memiliki peranan sangat penting dalam menentukan kandungan cadangan hara pada areal revegetasi lahan tambang. Menurut Prasetyo et al.
(2004), sifat fisika dan kimia tanah sangat dipengaruhi oleh peranan mineral tanah yang merupakan unsur utama sebagi penyusun tanah. Salah satu mineral yang terdapat dalam tanah, yaitu mineral fraksi pasir yang biasa disebut juga mineral primer.Mineral primer fraksi pasir ditemukan dalam tanah sebagai hasil pelapukan fisik dari batuan.Mineral primer merupakan mineral yang terbentuk dari hasil pengkristalan senyawa dalam magma akibat penurunan suhu. Komposisi dari beberapa mineral primer dapat digunakan sebagai indikator cadangan sumber hara dalam tanah.

Permasalahan yang menyangkut ketersediaan unsur hara dalam tanah bagi tanaman sangat ditentukan oleh komponen kimia tanah itu sendiri (Hakim et al., 1986).

Tujuan penelitian ini adalah untuk mengetahui komposisi fraksi pasir dan beberapa sifat kimia pada areal revegetasi kaitannya dengan cadangan hara, sehingga dapat dijadikan acuan untuk memperbaiki sifat kimia tanah dan fisika tanah.

\section{BAHAN DAN METODE}

Kegiatan penelitian dilakukan pada areal revegetasi lahan tambang batubara PT. Khotai Makmur Insan Abadi, Kabupaten Kutai 
Kartanegara, Provinsi Kalimantan Timur. Lokasi kawasan revegetasi seluas 18.37 ha, terletak pada posisi S $00^{\circ} 13^{\prime} 54,00^{\prime \prime} \mathrm{E} 117^{\circ} 08^{\prime} 22,90$ “. Jenis vegetasi yatiu Segon, Trembesi, Johar dengan umur tanaman 3 tahun. Penelitian dilaksanakan selama 6 bulan, mulai April sampai dengan Oktober 2019.

Bahan yang digunakan pada penelitian ini, yaitu sampel tanah yang diambil secara komposit dari setiap lapisan seberat $500 \mathrm{~g}$ dari 4 lapisan kedalaman 0-20 cm, 20-40 cm, 40-60 cm, 60-80 $\mathrm{cm}$ pada pada areal revegetasi PT. Khotai Makmur Insan Abadi, Kabupaten Kutai Kartanegara.

Alat yang digunakan dalam penelitian baik di lapangan maupun di laboratorium meliputi : tali rapiah, cangkul, meteran, GPS, spidol hitam, kantong platik, mikroskop polarisasi, dan alat-alat laboratorium kimia lainnya.

Analisis sifat kimia tanah di lakukan di Laboratorium Tanah, Fakultas Pertanian, Universitas Mulawarman. Analisis kimia tanah dilakukan untuk mengetahui status $\mathrm{pH}$ tanah, kandungan C-organik, Kapasitas Tukar Kation (KTK), Kejenuhan Basa, Kation-kation dapat tukar, Kejenuhan Al, penyebaran partikel tekstur 3 fraksi (pasir, debu, liat). $\mathrm{P}_{2} \mathrm{O}_{5}$ danK $_{2} \mathrm{O}$. Adapun metode dari analisis kimia tanah yaitu $\mathrm{pH}$ tanah dengan metode ekstraksi dengan perbandingan 1 : 2,5 dan diukur dengan menggunakan $\mathrm{pH}$ meter elektroda, C-organik ditetapkan dengan menggunakan metode Walkley dan Black diukur dengan menggunakan alat spektrofotometer, Kapasitas Tukar Kation (KTK) dan Kejenuhan Basa ditetapkan menggunakan ekstrak $\mathrm{NH}_{4} \mathrm{OAc}$ $1 \mathrm{M}, \mathrm{pH} 7.0$, basa-basa dapat tukar ( $\mathrm{Ca}, \mathrm{Mg}, \mathrm{K}$ dan $\mathrm{Na}$ ) dapat diketahui dengan memakai larutan $\mathrm{NH}_{4} \mathrm{OAc} 1 \mathrm{M}$, pH 7.0 dan diukur dengan memakai metode atomic absorption spectrophotometry, Fosfor dan Kalium dalam bentuk cadangan ditetapkan dengan menggunakan pengekstrak $\mathrm{HCl}$ $25 \%$.

Analisis komposisi mineral pasir dilakukan di Laboratorium Mineral BB Litbang SDLP Bogor dengan menggunakan mikroskop polarisasi. Sampel tanah seberat $500 \mathrm{~g}$ yang diambil dari setiap kedalaman yaitu: $0-20 \mathrm{~cm}, 20-40 \mathrm{~cm}, 40-$ $60 \mathrm{~cm}, 60-80 \mathrm{~cm}$. Perlakuan selanjutnya pencucian sampel tanah dengan dekstruksi menggunakan bahan kimia $\mathrm{H}_{2} \mathrm{O}_{2} 30 \%$ dan $\mathrm{HCl} 10 \%$, kemudian pasir disaring dengan ayakan $1-0.05 \mathrm{~mm}$, selanjutnya pemeriksaan dengan mikroskop polarisasi menggunakan metode line counting perhitungan sampai 100 butir.

\section{HASIL DAN PEMBAHASAN}

\section{Kandungan C-Organik}

Hasil analisis kandungan C-organik pada area revegetasi disajikan pada Tabel 1. Hasil analisis menunjukkan bahwa pada lokasi penelitian memiliki kandungan bahan organik tergolong sangat rendah sampai rendah, berkisar 0,76 hingga $1,90 \%$.

\section{Reaksi Tanah pH $\left(\mathrm{H}_{2} \mathrm{O}\right)$}

Reaksi tanah (Tabel 1.) pada lokasi revegetasi umumnya tergolong agak masam (6,05-6,49). Reaksi tanah mempengaruhi sifat biologi maupun sifat kimia tanah lainya, yaitu mempengaruhi aktivitas biota tanah dan mempengaruhi prosesproses yang terjadi di dalam tanah, seperti mempengaruhi pertumbuhan tanaman yaitu pengaruhnya terhadap ketersediaan unsur hara (Utomo et al.,2015; Yulius et al.,1997).

\section{Kation-Kation Basa}

Dari hasil analisis pada Tabel 2, kandungan $\mathrm{Ca}$ di lokasi revegetasi bervariasi dari rendah sampai sedang $(3,82-6,30 \mathrm{me} / 100 \mathrm{~g})$ Demikian pula dengan kandungan $\mathrm{Mg}$ tergolong rendah sampai sedang $(0,84-1,88 \mathrm{me} / 100 \mathrm{~g}) . \mathrm{Hal}$ ini disebabkan oleh karena tidak adanya mineral sumber $\mathrm{Mg}$ pada areal revegetasi. Menurut Prasetyo (2007), mineral yang merupakan sumber utama $\mathrm{Mg}$ adalah Olivin dan Augit.

Kandungan $\mathrm{K}$ pada daerah revegetasi tergolong rendah pada seluruh lapisan kedalaman, yaitu $0,16-0,37 \mathrm{me} / 100 \mathrm{~g}$

Hasil analisis Na yang disajikan pada Tabel 2, menunjukkn kandungan $\mathrm{Na}$ rendah( 0,14-0,29 me/100g) pada seluruh lapisan/kedalaman. Rendahnya kandungan Na dikarenakan kurangnya komposisi dari mineral plagioklas yang merupakan sumber utama $\mathrm{Na}$ pada areal revegetasi. Mineral Plagioklas termasuk mineral primer mudah lapuk yang apabila melapuk akan melepaskan hara makro ke dalam tanah, salah satunya Na (Pramuji dan Bustaman.,2009 ; Prasetyo et al.,2004 ; Tafakresnanto dan Prasetryo.,2001).

\section{Kapasitas Tukar Kation}

Kapasitas Tukar Kation (KTK) pada lokasi penelitian menunjukkan status rendah pada setiap lapisan, yaitu berkisar 5,54 sampai 8,41me/100g. Rendahnya kapasitas tukar kation di dalam tanah sangat erat hubungannya dengan kandungan mineral pasir (Prasetyo et al., 2004) dan rendahnya kandungan karbon organik.

\section{$P$ dan K Potensial}

Hasil analisis $\mathrm{P}$ dan $\mathrm{K}$ potensial disajikan pada Tabel 2. Kandungan Fosfor $\left(\mathrm{P}_{2} \mathrm{O}_{5}\right)$ pada areal revegetasi tergolong sedang sampai tinggi yaitu 
38,95 - 45,20 mg/100g, sedangkan kandungan Kalium $\left(\mathrm{K}_{2} \mathrm{O}\right)$ tergolong sedang pada semua kedalaman, yaitu $25,60-32,13 \mathrm{mg} / 100 \mathrm{~g}$.

Nilai KTK yang rendah, dan kandungan bahan organic (C-organik) pada lahan revegetasi dapat ditingkatkan dengan penambahan pupuk organik, yaitu kompos atau pupuk kandang (Noviardi dan Subardja,2013 ;Mashud dan Manaroinsong, 2014 ; Pattimahu, 2004)
Kejenuhan Basa dan Kejenuhan Aluminiun

Berdasarkan hasil analisis Kejenuhan Basa dan Kejenuhan Aluminium, menunjukkan bahwa pada kawasan revegetasi, memiliki kejenuhan basa yang sangat tinggi yaitu 97,62 -100\% . Kejenuhan Al pada daerah revegetasi tergolong sangat rendah, yaitu $0-1,67 \%$. Pernyataan kejenuhan diterapkan untuk menyatakan dominasi kation-kation basa, semakin tinggi kejenuhan basa maka semakin tinggi pH tanah (Utomo et al.,2015).

Tabel 1.pH, KTK, C-Organik, Kejenuhan Basa, Penyebaran Partikel

\begin{tabular}{|c|c|c|c|c|c|c|c|}
\hline \multirow[b]{2}{*}{$\begin{array}{c}\text { Kedalaman } \\
(\mathbf{c m})\end{array}$} & \multirow{2}{*}{$\begin{array}{c}\mathrm{pH} \\
\mathrm{H} 2 \mathrm{O} \\
\end{array}$} & \multirow{2}{*}{$\begin{array}{c}\text { KTK } \\
\text { me/100g } \\
\end{array}$} & \multirow[b]{2}{*}{$\begin{array}{c}\text { C-organik } \\
\%\end{array}$} & \multirow{2}{*}{$\begin{array}{c}\text { Kejenuhan Basa } \\
\% \\
\end{array}$} & \multicolumn{3}{|c|}{ Penyebaran Partikel } \\
\hline & & & & & Liat & $\begin{array}{c}\text { Debu } \\
\%\end{array}$ & Pasir \\
\hline $0-20$ & 6,05 & 8,41 & 1,03 & 97,62 & 14,98 & 33,35 & 51,67 \\
\hline $20-40$ & 6,49 & 5,54 & 0,76 & 100 & 14,39 & 27,34 & 58,27 \\
\hline $40-60$ & 6,07 & 7,09 & 1,47 & 100 & 12,57 & 27,75 & 59,68 \\
\hline $60-80$ & 6,13 & 7,79 & 1,90 & 100 & 12,30 & 30,01 & 57,69 \\
\hline
\end{tabular}

Sumber: Analisis Data Primer di Laboratorium Ilmu Tanah Faperta UNMUL

\section{Penyebaran Partikel (Pasir, Liat dan Debu)}

Berdasarkan hasil analisis yang disajikan pada Tabel 1, menunjukkan hasil penyeberan partikel pada lapisan atas tanah $(0-20 \mathrm{~cm})$ memiliki kandungan fraksi liat $14,98 \%$, debu $33,35 \%$, pasir $51,67 \%$, sehingga digolongkan pada kelas tekstur lempung. Pada lapisan 20-40, 40-60, 60-80 cm, memiliki kelas tekstur lempung berpasir dengan frkasi pasir > 57,69\%. Tingginya kandungan fraksi pasir disebabkan tanah pada areal revegetasi didominasi oleh mineral tahan lapuk, yaitu kuarsa, hal ini sejalan dengan pendapat Prasetyo et al.,2004, yang menyatakan bahwa tanah yang didominasi oleh mineral primer kuarsa mempunyai kecenderungan memiliki tekstur yang kasar (berpasir).

Tabel 2. Kejenuhan Al, Kation Basa, Kation Asam, $\mathrm{P}_{2} \mathrm{O}_{5}, \mathrm{~K}_{2} \mathrm{O}_{5}$

\begin{tabular}{|c|c|c|c|c|c|c|c|c|c|}
\hline \multirow{3}{*}{$\begin{array}{c}\text { Kedalaman } \\
\text { (cm) }\end{array}$} & \multirow{3}{*}{$\begin{array}{c}\text { Kejenuhan } \\
\mathrm{Al} \\
\%\end{array}$} & \multicolumn{4}{|c|}{ Kation Basa(pH 7) } & \multicolumn{2}{|l|}{$\begin{array}{c}\text { Kation } \\
\text { Asam }\end{array}$} & \multirow{2}{*}{$\begin{array}{c}\mathrm{P} 2 \mathrm{O} 5 \\
\mathrm{HCl} \\
25 \%\end{array}$} & \multirow{2}{*}{$\begin{array}{l}\mathrm{K} 2 \mathrm{O} \\
\mathrm{HCL} \\
25 \%\end{array}$} \\
\hline & & $\mathrm{Ca}^{2+}$ & $\mathrm{Mg}^{2+}$ & $\mathrm{K}^{+}$ & $\mathrm{Na}^{+}$ & $\mathrm{Al}^{3+}$ & $\mathrm{H}^{+}$ & & \\
\hline & & \multicolumn{5}{|c|}{$\mathrm{me} / 100 \mathrm{~g}$} & $\%$ & $\mathrm{mg} / 100 \mathrm{~g}$ & $\mathrm{mg} / 100 \mathrm{~g}$ \\
\hline $0-20$ & 1,67 & 5,92 & 1,88 & 0,20 & 0,21 & 0,14 & 0,06 & 39,99 & 26,11 \\
\hline $20-40$ & 0,00 & 3,82 & 1,42 & 0,16 & 0,14 & 0,00 & 0,00 & 45,21 & 25,61 \\
\hline $40-60$ & 0,00 & 5,53 & 1,06 & 0,32 & 0,18 & 0,00 & 0,00 & 38,95 & 32,13 \\
\hline $60-80$ & 0,00 & 6,30 & 0,84 & 0,37 & 0,29 & 0,00 & 0,00 & 40,62 & 31,13 \\
\hline
\end{tabular}

Sumber: Analisis Data Primer di Laboratorium Ilmu Tanah Faperta UNMUL

\section{Komposisi Mineral Fraksi Pasir}

Mineral fraksi pasir disebut juga mineral primer. Mineral primer kuarsa dan opak merupakan mineral fraksi pasir yang banyak ditemukan di Indonesia ( Pramuji\& Bustaman, 2009). Hasil analisis komposisi fraksi pasir yang disajikan pada Tabel 3, menunjukkan bahwa komposisi mineral fraksi pasir pada lokasi revegetasi didominasi oleh mineral kuarsa (mineral tahan lapuk), dan dalam jumlah sedikit dijumpai opak, zirkon dan turmalin. Dominasi mineral kuarsa pada areal revegetasi mencapai
$82 \%$.Pada areal revegetasi tidak dijumpai mineral mudah lapuk, yang menunjukkan bahawa cadangan sumber hara dalam tanah telah habis (Pramuji \& Bustaman, 2009). Hal ini menunjukkan bahwa keberadaan mineral resisten yang dominan dalam tanah pada daerah revegetasi menjadi indikatormiskinnya cadangan sumber hara dalam tanah atau dengan kata lain tanah memiliki cadangan hara yang rendah.

Menurut Prasetyo at al.,2004, untuk mengetahui tingkat perkembangan lanjut tanah serta stabilitas yang tinggi terhadap pelapukkan, 
juga dapat diketahui melalui keberadaa mineral

resisten yaitu mineral kuarsa dalam tanah.

Tabel 3. Komposisi Mineral Fraksi Pasir

\begin{tabular}{|c|c|c|c|c|c|c|c|c|c|c|c|c|c|c|c|}
\hline $\begin{array}{l}\text { Kedalaman } \\
\text { (cm) }\end{array}$ & Op & $\mathbf{Z i}$ & $\mathbf{K u}$ & $\mathbf{L m}$ & $\mathbf{F b}$ & $\mathbf{G v}$ & Ol & An & Or & Sn & Am & $\mathbf{E p}$ & $\mathbf{T u}$ & En & Total \\
\hline $0-20$ & 2 & 3 & 81 & 3 & 4 & - & - & - & - & - & - & - & 1 & - & 100 \\
\hline $20-40$ & 3 & 4 & 77 & 2 & 5 & - & - & - & - & - & - & - & - & - & 100 \\
\hline $40-60$ & 3 & 2 & 80 & 1 & 5 & - & - & - & - & - & - & - & 1 & - & 100 \\
\hline $60-80$ & 2 & 3 & 82 & 2 & 4 & - & - & - & - & - & - & - & - & - & 100 \\
\hline
\end{tabular}

Keterangan:- $=$ tidak ditemukan, $\mathrm{Op}=\mathrm{Opak}, \mathrm{Zi}=\mathrm{Zirkon}, \mathrm{Ku}=\mathrm{kuarsa}, \mathrm{Lm}=$ lapukan mineral, $\mathrm{Fb}=$ Ffragment batuan, $\mathrm{Gv}=$ Gelas volkan, Ol=Oligoklas, $\mathrm{An}=$ Andesin, Or=Orthoklas, $\mathrm{Sn}=$ Sanidin, $\mathrm{Am}=$ Amfibol, Ep=Epidot, Tu=Turmalin En=Enstatin

\section{KESIMPULAN}

Berdasarkan hasil analisis kimia dan komposisi fraksi pasir pada areal revegetasi dapat ditarik kesimpulan:

1. Komposisi mineral fraksi pasir pada areal revegetasi didominasi oleh mineral tahan lapuk, yaitu kuarsa, dalam jumlah sedikit opak, zircon, lapukan mineral, fragmen batuan dan turmalin. Hal ini menunjukkan bahwa tanah pada areal revegetasi lahan bekas tambang batubara tidak memiliki potensi cadangan sumber hara dalam tanah.

2. Hasil analisis kimia tanah pada area revegetasi menunjukkan reaksi tanah $(\mathrm{pH})$ yang tergolong agak masam $(6,05-$ 6,49), Kapasitas Tukar Kation Kation yang rendah pada seluruh kedalaman (5,54 -8,41 me/100g)., kandungan Corganic tergolong sangat rendah sampai rendah (0,76-1,90 me/100g), rendah sampai sedang kandungan kation basa $\mathrm{Ca}$ dan $\mathrm{Mg}$, rendahnya kadungan kation $\mathrm{K}$ dan $\mathrm{Na}$ pada seluruh kedalaman, kandungan $\mathrm{P}$ potensial yang bervariasi dari sedang sampai tinggi, $\mathrm{K}$ potensial torgolong sedang pada semua lapisan. Penyebaran partikel termasuk dalam kelas tekstur lempug, dan lempung berpasir. Perlunya usaha peningkatan kandungan unsur hara berupa pemupukan dan usaha penigkatan $\mathrm{pH}$ dengan pengapuran pada area revegetasi.

\section{UCAPAN TERIMA KASIH}

Penulis mengucapkan terima kasih kepada Deka Fakultas Pertanian, Prof.DR. Ir. H. Rusdiansyah, M.Si, yang telah memberikan kesempatan kepada penulis untuk melaksanakan penelitian. Penulis juga mengucapkan terima kasih yang sebesarbesarnya kepada PT. Khotai Makmur Insan Abadi atas kerjasamanya dalam pelaksanaan penelitian. Dan pada akhirnya penulis juga taklupa mengucapkan terima kasih kepada semua pihak yang telah membantu dalam pelaksanaan penelitan baik di lapangan maupun di laboratorium.

\section{DAFTAR PUSTAKA}

Budiana, I.G.E., Jumani.,\& Biantary, M.P. (2017). Evaluasi Tingkat Keberhasilan Revegetasi Lahan Bekas Tambang Batubara di PT.Kitadin Site Embalut Kabuten Kutai Kartanegara Kalimantan Timur.

Hakim, N.,Nyakpa,Y.,Lubis, A.M., Nugroho, S.G.,Diha, M.A.,Hong, G.B, \& Bailey, H.H. (1986). Dasar-Dasar Ilmu Tanah. Universitas Lampung.

Mashud,N.,\& Manaroinsong, E. (2014). Pemanfaatan Lahan Bekas Tambang Batu Bara Untuk Pengembangan Sagu. Balai Penelitian Tanaman Palma. Vol.15.no.1 56-63

Noviardi, R.,\& Subardja, A. (2013). Kesuburan Tanah Pada Area Revegetasi Paska Penambangan Nikel Di UBP.Nikel Pomala PT.Aneka Tambang, Tbk. Prosiding Pemaparan Hasil Penelitian Puslit GeoteknologiLIPI.

Pattimahu, D. V. (2004). Restorasi Lahan Kritis Pasca Tambang Sesuai Kaidah Ekologi. Makalah Falsafah Sarjana Sains (PPS 702). Institut Pertanian Bogor. 
J. Agrifarm : Vol. 8 No. 2, Desember 2019 P- ISSN : 2301-9700, E- ISSN : 2540-8892

Peraturan Menteri ESDM Republik Indonesia Nomor 07 Tahun 2014.Tentang Pelaksanaan Reklamasi dan Pasca Tambang Pada Kegiatan Usaha Pertambangan Mineral dan Batubara.

Pramuji \& Bastaman.M.(2009). Teknik Analisis Mineral Tanah Untuk Menduga Cadangan Sumber Hara. Buletin Teknik Pertanian. Vol. 14.N0.2.80-82

Prasetyo, B.H. (2007). Perbedaan Sifat-Sifat Tanah Vertisol Dari Berbagai Lahan Induk.Jurnal Ilmu-Ilmu Pertanian Indonesia. Volume 9.No.1. Hlm. 20-31.

Prasetyo, B.H., J.S. Adiningsih, K. Subagyono, \& R.D.M. Simanungkalit. (2004). Mineralogi, Kimia, Fisika dan Biologi Lahan Sawah. Hlm. 36-50. Dalam F. Agus (Wd.) Lahan Sawah dan Teknologi Pengelolaanya.Pusat Penelitian Tanah dan Agroklimat, Bogor.

Tafakresnanto,C.\&B.H.Prasetyo. (2001). Peranan Data Mineral Tanah Dalam Menunjang Interpretasi Sumber Daya Tanah. Jurnal Tanah dan Air 2(1): 4756.

Utomo,M.,Sudarsono.,Rusman,B.,Sabrina,T. , Lumbanraja,J.,\&wawan. (2015).

Ilmu Tanah. Dasar-Dasar dan Pengelolaan. Bandar Lampung. Yulius,

.P.,Nanere,J.L.,Samosir,S.S.R.,Tangka isari,R.,Lalopua,J.R.,Ibrahim,B.,\& Asmadi,H. (1997). Dasar-Dasar Ilmu Tanah. Departemen Pendidikan dan Kebudayaan Direktorat Jendral Pendidikan Tinggi Badan Kerjasama Perguruan Tinggi Negeri Indonesia Timur. 
